\title{
The role of the QBO in the inter-hemispheric coupling of summer mesospheric temperatures
}

\author{
P. J. Espy ${ }^{1}$, S. Ochoa Fernández ${ }^{1,4}$, P. Forkman ${ }^{2}$, D. Murtagh ${ }^{2}$, and J. Stegman ${ }^{3}$ \\ ${ }^{1}$ Norwegian University of Science and Technology, Trondheim, Norway \\ ${ }^{2}$ Chalmers University of Technology, Göteborg, Sweden \\ ${ }^{3}$ Stockholm University, Stockholm, Sweden \\ ${ }^{4}$ University of Cantabria, Santander, Spain
}

Received: 20 August 2010 - Published in Atmos. Chem. Phys. Discuss.: 11 October 2010

Revised: 22 December 2010 - Accepted: 23 December 2010 - Published: 17 January 2011

\begin{abstract}
Inter-hemispheric coupling between the polar summer mesosphere and planetary-wave activity in the extratropical winter stratosphere has recently been inferred using Polar Mesospheric Cloud (PMC) properties as a proxy for mesospheric temperature (Karlsson et al., 2007). Here we confirm these results using a ten-year time series of July mesospheric temperatures near $60^{\circ} \mathrm{N}$ derived from the hydroxyl $(\mathrm{OH})$ nightglow. In addition, we show that the time-lagged correlation between these summer mesospheric temperatures and the ECMWF winter stratospheric temperatures displays a strong Quasi-Biennial Oscillation (QBO). The sign and phase of the correlation is consistent with the QBO modulation of the extra-tropical stratospheric dynamics in the Southern Hemisphere via the Holton-Tan mechanism (Holton and Tan, 1980). This lends strength to the identification of synoptic and planetary waves as the driver of the inter-hemispheric coupling, and results in a strong QBO modulation of the polar summer mesospheric temperatures.
\end{abstract}

\section{Introduction}

As atmospheric gravity waves propagate upwards, they are filtered by the geostrophic zonal winds of the stratosphere, resulting in a net wave momentum flux to the mesosphere that is in the opposite direction to the stratospheric winds (Fritts and Alexander, 2003). These waves grow in amplitude as they propagate into the rarefied mesosphere, and some become unstable and locally dissipate their energy and de-

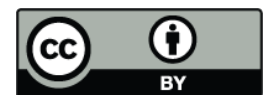

Correspondence to: P. J. Espy

(patrick.espy@ntnu.no) posit their momentum as they break. This input of momentum creates a drag force on the zonal wind that establishes a pole-to-pole circulation in the mesosphere (Lindzen, 1981; Holton, 1982, 1983; Garcia and Solomon, 1985). The resulting wintertime convergent and downward flow, and the corresponding summertime divergent and upward flow, adiabatically drive the polar mesospheric temperatures far from radiative equilibrium and create a warm winter and cold summer mesopause in the polar regions (Haurwitz, 1961; Garcia and Solomon, 1985; Lübken et al., 1990; Fritts and Luo, 1995; Luo et al., 1995; Espy and Stegman, 2002; Fritts and Alexander, 2003). This adiabatic cooling drives the summer polar mesopause temperatures below $150 \mathrm{~K}$, and the small amounts of water vapour present can condense into the ice clouds known as Polar Mesospheric Clouds (PMC).

The strength of this inter-hemispheric circulation, and thus the degree of heating or cooling at the polar mesopause, depends upon the net amount gravity-wave momentum flux deposited in the mesosphere. Hence, stronger stratospheric zonal winds result in a more complete filtering of the waves, giving a higher net gravity-wave momentum flux and a stronger residual circulation, and vice versa (Holton, 1982, 1983). During the winter, planetary-wave breaking can disrupt the stratospheric zonal flow and its wave filtering, decreasing the strength of this inter-hemispheric circulation and its resultant heating and cooling (Becker et al., 2004). The extreme stratospheric planetary-wave activity during the Antarctic winter of 2002, which eventually led to the unusual major stratospheric warming, has been cited by Becker et al. (2004) as a possible cause of the decrease in the occurrence frequency of Northern Hemisphere PMC observed by the SNOE satellite (Bailey et al., 2005).

Published by Copernicus Publications on behalf of the European Geosciences Union. 
Karlsson et al. (2007) examined the year to year variability of the polar summer mesosphere and found a strong correlation between the radii of PMC, used as a proxy for the temperature of the mesosphere, and the winter stratospheric temperatures that were used as a proxy for the residual circulation in the stratosphere. They found that warmer stratospheric temperatures in the winter hemisphere, an indicator of increased planetary wave activity, could be associated with warm anomalies of the summer mesospheric temperatures in the opposite hemisphere. These observations, along with modelling studies (Karlsson et al., 2009; Körnich and Becker, 2010), suggested that planetary-wave activity in the winter hemisphere was the cause of the disruption in the inter-hemispheric flow and the variation in the summertime mesopause temperatures. However, as there are many factors that can influence the size of PMC in a non-linear manner, we repeat this correlation analysis using a time series of temperatures near the mesopause derived from observations of the hydroxyl infrared nightglow near $60^{\circ} \mathrm{N}$. The mesospheric temperature data stretch over ten Northern-Hemisphere summer seasons, and the July average temperature is used for the correlation analysis. The time-lagged correlations with the July, Southern Hemisphere stratospheric temperatures from the ERA-40 re-analysis data from the European Centre for Medium range Weather Forecasting (ECMWF) are examined for QBO modulation effects. Since the QBO in an easterly phase would direct synoptic- and planetary-wave activity towards the winter pole and slow the zonal mean flow (Holton and Tan, 1980; Dunkerton and Baldwin, 1991; Salby et al., 1997; Baldwin and Dunkerton, 1998; Kuroda and Kodera, 2001), a QBO modulation of the inter-hemispheric coupling effect would provide further mechanistic evidence that it is the Southern Hemisphere planetary-wave activity during winter that modulates the temperatures at the summer mesopause.

\section{Instrumentation and observations}

\subsection{Hydroxyl nightglow}

Michelson interferometer observations of the $\mathrm{OH}$ Meinel $(3,1)$ band nightglow were made in the spectral region between 1475 and $1527 \mathrm{~nm}$ at $\sim 0.5 \mathrm{~nm}$ resolution in order to derive its rotational temperature. Since the low-lying rotational levels of this band are in thermal equilibrium with the surrounding atmosphere (Pendleton et al., 1993), these temperatures were taken to be the average neutral temperature over the 8-km-thick OH layer centred near $87 \mathrm{~km}$ (Baker and Stair, 1988). The instrument operated in the near infrared, allowing $\mathrm{OH}$ radiance and temperature measurements to be obtained at solar zenith angles greater than $95^{\circ}$. The measurements were made from Stockholm, Sweden $\left(59.5^{\circ} \mathrm{N}\right.$, $18.2^{\circ} \mathrm{E}$ ) during the summers of 1991 and 1993, and then continuously from 1993 through 1998. After 1998, the in- strument was moved to Onsala, Sweden $\left(57.4^{\circ} \mathrm{N}, 11.9^{\circ} \mathrm{E}\right)$, and data collection continued through 2000.

The interferometer scanned each interferogram in $\sim 3 \mathrm{~s}$, but added scans in memory to yield an integration period of between $\sim 5$ and $\sim 15 \mathrm{~min}$ for each spectrum, depending upon the radiance levels. Due to scattered light, data could only be acquired whenever the sun was more than $5^{\circ}$ below the horizon. This gave from $\sim 3.5$ to $\sim 5.5 \mathrm{~h}$ of observation time each night over the course of July. Both a $1000 \mathrm{~K}$ blackbody and transfer standard were used to generate the spectral responses, and the $\mathrm{OH}$ line positions of Maillard et al. (1976) were used to calibrate the wavelength scales. Details of these spectral and wavelength calibrations are described in Espy and Stegman (2002).

Espy et al. (1995) describe in detail the spectral fitting technique used on the data. In brief, the spectral region of the $(3,1)$ Meinel vibration-rotation band was modelled using a synthetic hydroxyl spectrum and a model generated scattered solar spectrum (Berk, 1989). The hydroxyl spectrum was generated by convolving the instrumental line-shape function with the line strengths of Mies (1974), using a Boltzmann model of the rotational-level populations. The rotational temperature, integrated band strength and a scaling for the solar scatter were then adjusted to give a best, leastsquares fit to the data (Hill et al., 1979). In order to remove the contribution of continuum radiation, both the data and the model were high-pass filtered before fitting. Using a sample of data obtained under clear-sky conditions the relative uncertainty estimates for the individual fits of integrated band radiance and rotational temperature were typically on the order of $1-3 \%$ and $3-5 \%$, respectively. Data periods obscured by clouds were marked by a significantly reduced signal-tonoise, resulting in the fitting routine either failing to converge or converging with large uncertainty estimates. It was empirically determined that error estimates three-sigma larger than those of the clear-sky data were contaminated by cloud and dropped from the analysis.

After processing, the individual 5 to $15 \mathrm{~min}$ temperature values were combined to form a single nightly average. This averaging, as well as the monthly averaging described below, had the effect of smoothing out the variations caused by short-period gravity waves. However, during individual nights, the $\mathrm{OH}$ temperature can vary by $3-5 \%$ due to both photo-chemical and tidal effects (Lowe et al., 1996). Therefore, in order to prevent data gaps caused by cloudy periods during the night from skewing the average, nights with less than 100 min of data were not included in the analysis. On average, each night used in the analysis covered $89-93 \%$ of the possible observation time, with a minimum data coverage of $30 \%$. 


\subsection{Stratospheric temperatures}

Karlsson et al. (2007) used the lower stratospheric temperatures in the winter hemisphere as a proxy for the residual circulation. It should be noted that the mechanisms proposed for inter-hemispheric coupling rely on changes in the zonal wind field, not the temperature. However, the zonal wind has large latitudinal gradients compared to the temperature field. Thus, the zonal average of temperature is more stable against year-to-year variations in the location and asymmetry of the vortex than that of the zonal wind. For that reason, and in keeping with the Karlsson et al. (2007) analysis, we use the zonally averaged, monthly mean, lower stratospheric temperatures from the ECMWF ERA-40 re-analysis (Uppala et al., 2005) as the primary characterization of the dynamic state of the winter stratosphere during the mesospheric data period: July 1991 through July 2000. As the data are for the Southern Hemisphere, where variations occur mainly on the vortex edge (Baldwin and Dunkerton, 1998; Kuroda and Kodera, 2001; Karlsson et al., 2007), the data are averaged over the latitudinal band from 40 to $60^{\circ} \mathrm{S}$. The data cover the altitude range from 1000 to $1 \mathrm{hPa}$ (approximately 0 to $50 \mathrm{~km}$ ) in 23 steps, and the correlation analysis with the summer mesospheric temperatures is performed at each pressure level.

\subsection{QBO winds}

The QBO data used in this article are taken from the 19-level, high-resolution merged data set of monthly means available from the Max Planck Institute for Meteorology, Hamburg (http://www.pa.op.dlr.de/CCMVal/Forcings/qbo_data ccmval/u_profile_195301-200412.html) between 1953 and 2004. Although the QBO winds have been extended from 90 to $3 \mathrm{hPa}$, the propagation method to vertically extend the winds provides useful information only to $5 \mathrm{hPa}$ (Giorgetta et al., 2002). For that reason, only the 17 pressure levels between 90 and $5 \mathrm{hPa}$ (approximately 16 to $35 \mathrm{~km}$ ) were used in the analysis. The July monthly-mean QBO winds between 1991 and 2000 were correlated with the mesospheric temperatures at each of these levels.

\section{Analysis and results}

Due to seasonal and longer time-scale variations, the temperature and wind data were de-trended prior to any correlation analysis. The nightly-averaged mesospheric temperatures were averaged for each day-of-year (DoY) over the period from 1991 through 2000. The resulting average seasonal behaviour is shown in Fig. 1, along with the number of individual observations present each DoY. Although there is a large seasonal variation, the temperatures are stable during the July period (days 182-212). Nevertheless, a harmonic fit to the data was used to remove the mean and significant periodic components on a DoY basis.
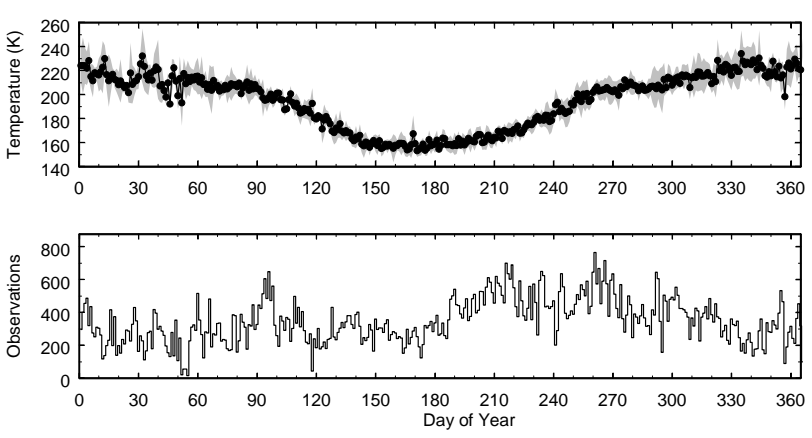

Fig. 1. The upper panel shows the seasonal changes of the mesospheric temperature around $60^{\circ} \mathrm{N}$ inferred from the hydroxyl nightglow. The shaded regions show the standard error of the mean for each night. The lower panel shows the number of individual observations that comprise the average temperature shown above.

In addition to seasonal changes, it has been shown that variations in solar activity can affect the magnitude of hydroxyl-derived temperatures (Pertsev and Perminov, 2007). Thus, a regression analysis between the individual nightly-mean temperatures and the corresponding F10.7 flux (in solar flux units) was performed, and the resulting solar attributable signal, $2.0 \pm 0.4 \times 10^{-2} \mathrm{~K} / \mathrm{sfu}$, was removed from the data before the monthly means for July were formed. The resulting July-mean mesospheric temperature anomaly from 1991 through 2000 is shown in Fig. 2.

Although the Southern Hemisphere stratospheric temperatures between 40 and $60^{\circ} \mathrm{S}$ do not show a significant solarcycle variation, they do display long term trends (Randel et al., 2009). Thus, an average and linear trend were fitted and removed from the July-mean temperatures. As an example, the resulting $50 \mathrm{hPa}$ temperature anomalies from 1991 through 2000 are also shown in Fig. 2.

Finally, while the QBO-wind anomaly shows a frequency modulation dependent upon solar cycle, its amplitude shows no systematic change (Salby and Callaghan, 2000). Thus, no solar cycle correction was applied to the data. Instead, at each pressure level, the mean July value, averaged over the years 1991 to 2000, was subtracted from the individual months before performing the correlation analysis. The resulting July, monthly-mean, QBO-anomaly data at $50 \mathrm{hPa}$ are also shown in Fig. 2 (note the vertical scale is reversed for the QBO winds).

Upon examination of the data in Fig. 2, the stratospheric and mesospheric temperatures clearly vary together year-toyear and are highly correlated. When those variations are compared to the QBO wind anomaly, it is clear that the apparent correlation between the temperatures is due almost entirely to a QBO modulation of those signals. This is particularly apparent for the years 1999 and 2000, where the asynchrony between the QBO and the yearly cycle results in the same QBO phase during those two summers. This 


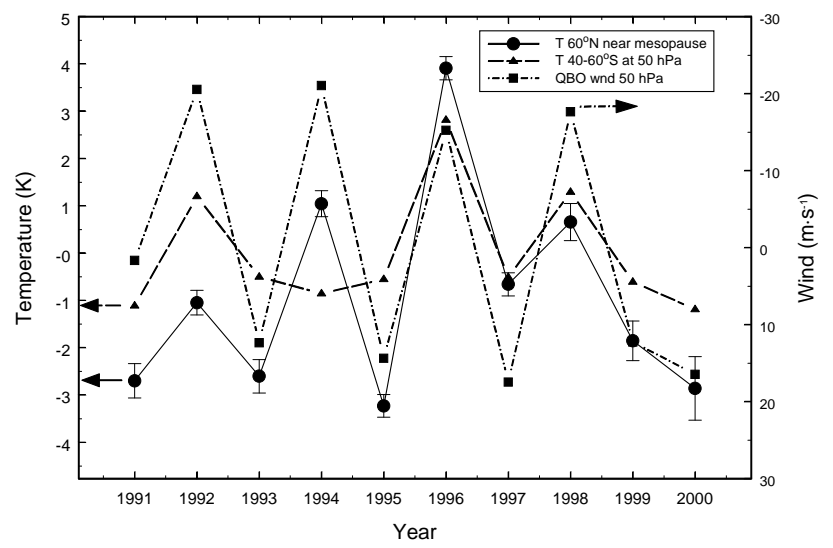

Fig. 2. The summer mesospheric temperature anomaly near $87 \mathrm{~km}$ (circle-solid line), winter stratospheric temperature anomaly at $50 \mathrm{hPa}$ (triangle-dashed line) and the QBO wind anomaly at $50 \mathrm{hPa}$ (square-dashed and dotted line) as a function of year. For the winds, negative denotes an easterly (towards the west) direction, and the axis has been reversed.

is mirrored by the low temperature anomalies for those two years. In fact, the coefficient of linear correlation between the stratospheric and mesospheric temperatures shown in Fig. 2 is $r=0.8$, significant at the $99 \%$ level. Similarly, the linear correlation coefficient between the mesospheric temperatures and the QBO wind anomaly is $r=0.7$, significant at the $98 \%$ level.

In order to see if the correlation between the mesospheric and stratospheric temperatures is driven by a QBO modulation, a time-lagged cross-covariance analysis (the cross-correlation of mean-removed data sequences) was performed. Figure 3a shows the cross-covariance between the Northern Hemisphere summer mesopause temperature and the Southern Hemisphere winter stratospheric temperatures as a function of stratospheric height and time lag between the data sequences. At zero lag, the cross-covariance is positive at all altitudes indicating that the temperatures are correlated. The average magnitude of the cross-covariance over the entire altitude range from 1 to $1000 \mathrm{hPa}$ between these two data sets is $r=0.5$, with a maximum magnitude of $r=0.8$, similar to the results found by Karlsson et al. (2007) using the PMC proxy for mesospheric temperature. If we restrict ourselves to the approximate altitude region over which QBO data are available, $5-100 \mathrm{hPa}$, the average cross-covariance shown in Fig. $3 \mathrm{~b}$ increases to 0.6 with the maximum magnitude remaining at $r=0.8$. The time-lagged cross-covariance over this restricted altitude range is shown in Fig. 3b.

With increasing or decreasing time lag, the correlation may be seen to change from positive to negative approximately every year over the entire altitude range. In fact, periodogram analyses of the time-lagged covariance at 10 and $50 \mathrm{hPa}$, confirmed by maximum entropy analyses, show this variation to have a period of 2.1 years. This is exactly the
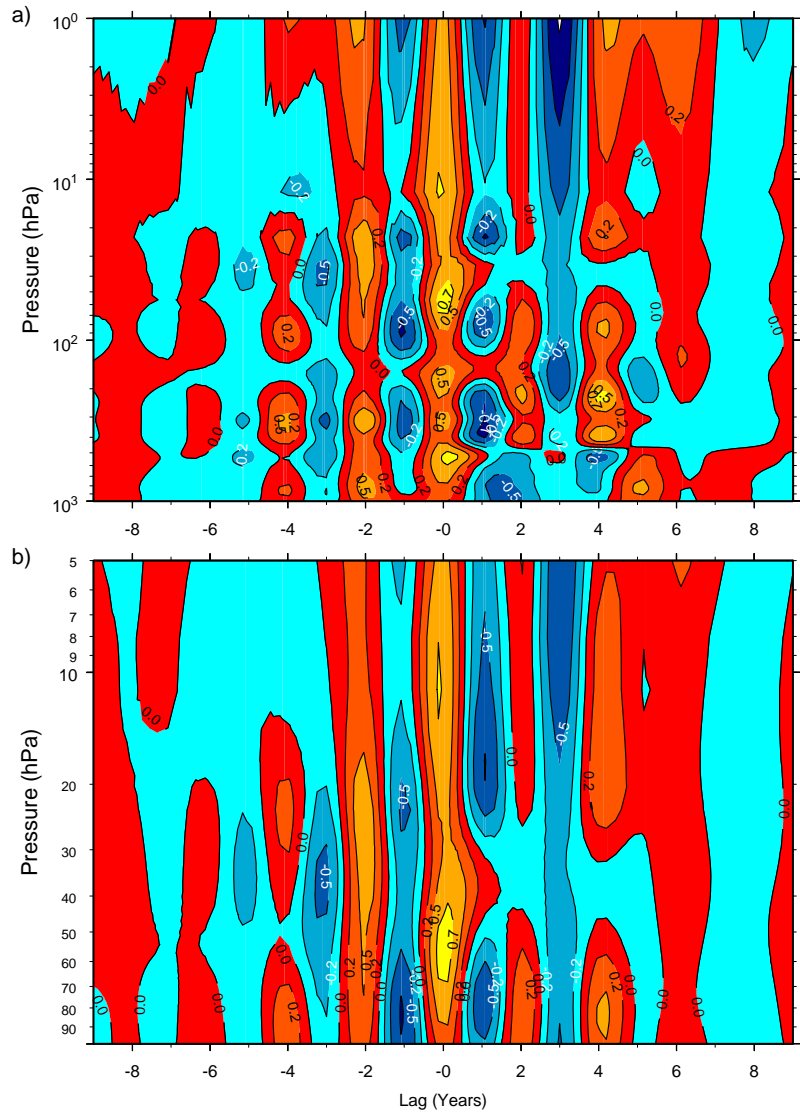

Fig. 3. Top panel (a) shows the time-lagged cross-covariance between the summer mesospheric temperatures and each level of the winter stratospheric temperatures between 1000 and $1 \mathrm{hPa}$. Negative lags correspond to the mesospheric temperatures leading the stratospheric temperatures. The lower panel (b) shows the same data but restricted to approximately the same altitude range over which QBO data are available, 100 to $5 \mathrm{hPa}$. Blue denotes negative (anti-correlation) and red denotes positive (correlation).

same period given by time-series analyses of the $\mathrm{QBO}$ winds over the years from 1991 to 2000 . Thus, during this time period, there is a phase-coherent oscillation in both the summer mesopause temperatures and the winter stratospheric temperatures that is in-phase over all altitudes, and this oscillation has the same period as the QBO. The phase of the oscillation is such that the summer mesopause and winter stratospheric temperature anomalies are warmer during years when the QBO is in the easterly phase at $50 \mathrm{hPa}$, and colder during the QBO westerly phase.

A number of workers have found and explained this QBO signal in the wintertime polar and extra-tropical stratospheric temperatures (Holton and Tan, 1980; Dunkerton and Baldwin, 1991; Salby et al., 1997; Baldwin and Dunkerton, 1998; Kuroda and Kodera, 2001). Conversely, although variations in mesospheric temperatures commensurate with the QBO period have been identified in some investigations (Espy and 
Stegman, 2002; Shepherd et al., 2004, 2006; Xu et al., 2007), many studies report no significant QBO signals in continuous time series of mid- to high-latitude hydroxyl temperatures (Bittner et al., 1998, 2000, 2002; French and Burns, 2004). However, Fig. 2 shows that the variations in the $50 \mathrm{hPa}$ QBO wind anomalies and the annually-sampled, summertime mesospheric temperature anomalies are strikingly similar, and as reported above, have a coefficient of linear correlation $r=0.7$ significant at the $98 \%$ level. We have therefore repeated the time-lagged cross-covariance between the summer polar mesosphere temperatures and the QBO over the full altitude range of the QBO wind data, 90 to $5 \mathrm{hPa}$, and the results are shown in Fig. 4.

At zero lag, Fig. 4 shows that the cross-covariance switches from a maximum anti-correlation of $r=-0.8$ below $15 \mathrm{hPa}$, to a maximum correlation of $r=+0.8$ above. This is consistent with the phase change of the QBO between the stratosphere and mesosphere (Burrage et al., 1996; Baldwin et al., 2001). Thus, while the warm anomaly in the summertime polar mesospheric temperatures is associated with a westerly phase of the Mesospheric QBO (MQBO), it occurs during an easterly phase of the Stratospheric QBO (SQBO).

With increasing or decreasing time lag, the correlation may be seen to change sign approximately every year. In fact, periodogram analyses of the time-lagged covariance at both 10 and $50 \mathrm{hPa}$, confirmed by maximum entropy analyses, show this variation to have a period of 2.1 years, in agreement with the stratospheric temperature analysis given above. This is again the same period given by a time-series analysis of the QBO winds over the years from 1991 to 2000 . Thus, during this time period, there is a phase-coherent oscillation with a period of 2.1 years in both the summer mesopause temperatures and the $\mathrm{QBO}$ winds. The oscillations are in phase above $15 \mathrm{hPa}, 90^{\circ}$ out of phase at $15 \mathrm{hPa}$, and in anti-phase below that level.

Baldwin and Dunkerton (1998) observed that due to the relatively weak Southern Hemisphere planetary wave field, the QBO-induced variations in the zonal wind occur mainly at the vortex edge $\left(\sim 40-60^{\circ} \mathrm{S}\right)$ at altitudes near $5 \mathrm{hPa}$. To check whether the temperature proxy for the residual circulation used here captures the behaviour of the wind field, we have compared the Northern Hemisphere mesospheric temperatures to zonal averages of the ERA-40 zonal wind over the same latitudinal range, 40 to $60^{\circ} \mathrm{S}$. Despite the increased variability mentioned previously, we find that these zonally averaged ERA-40 zonal winds are on average $3.4 \mathrm{~m} \mathrm{~s}^{1}$ slower during years with the warm mesospheric temperature anomaly that is associated with the easterly phase of the QBO. We also find that the effect maximizes at $5 \mathrm{hPa}$, in agreement with the Baldwin and Dunkerton (1998) results.

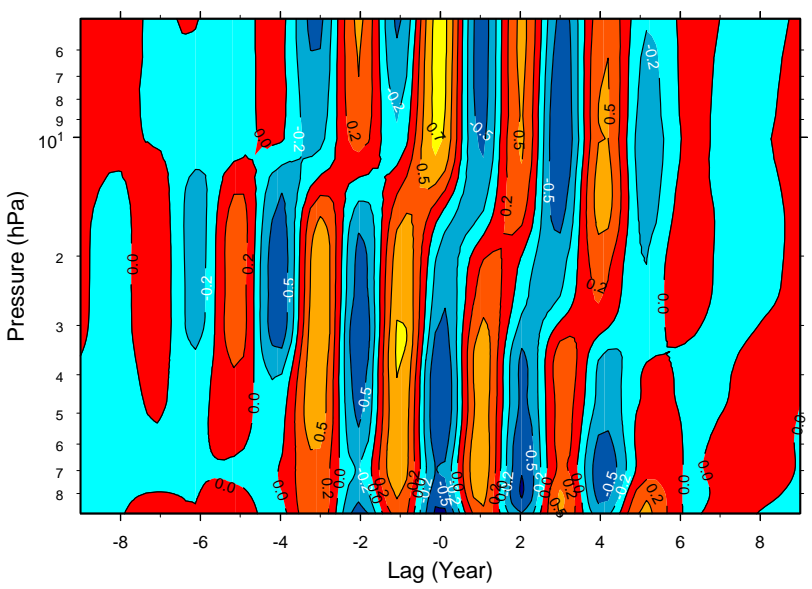

Fig. 4. The time-lagged cross-covariance between the summer mesospheric temperatures and each level of the QBO wind from 90 to $5 \mathrm{hPa}$. Blue denotes negative (anti-correlation) and red denotes positive (correlation).

\section{Discussion and conclusions}

The primary result of this investigation has been to confirm the inter-hemispheric correlation found by Karlsson et al. (2007) between the polar temperatures in the winter stratosphere and the summer mesosphere using observations of the summer mesospheric temperature rather than temperature proxies based on PMC properties. More significantly, we have demonstrated that this correlation occurs due to a phase-coherent modulation of the temperatures in each hemisphere by the QBO. As a result of this modulation, the warm temperature anomalies in the winter polar stratosphere and the summer polar mesosphere coincide with the easterly phase of the SQBO.

The importance of this latter result is that it confirms the role of synoptic and planetary waves as the primary agent of the inter-hemispheric coupling as suggested by Becker et al. (2004) and Karlsson et al. (2009). There, it is proposed that when the flux of planetary-wave is larger in the winter hemisphere, it perturbs the winter polar-vortex winds, which results in less gravity-wave filtering, a weaker residual circulation, less adiabatic divergence in the polar summer mesopause and correspondingly warmer temperatures there. The phase of the QBO modulation of the polar temperatures found in this investigation is consistent with earlier findings that the polar winter vortex is warmer and weaker during the easterly phase of the SQBO due to the movement of the zero wind line, the critical line for synoptic and planetary waves, into the winner hemisphere (Holton and Tan, 1980; Mcintyre, 1982; O'Sullivan and Salby, 1990; O'Sullivan and Young, 1992). The proximity of the critical line to the polar vortex results in more absorption of planetary-wave energy and eddy mixing that perturb the vortex and leads to warmer polar temperatures and weaker 
vortex winds. Thus, our finding of a QBO modulation of the summer stratospheric and winter mesospheric temperatures, with the warmer anomalies present during the easterly SQBO phase, support the proposed mechanism.

This study has also shown a strong QBO modulation of the polar summer mesospheric temperatures in contradiction to several ground-based $\mathrm{OH}$ temperature observations in the Antarctic (French and Burns, 2004) and at northern midlatitudes (Bittner et al., 1998, 2000, 2002). There would be two mechanisms of communicating the QBO signal to the polar regions via the planetary-wave weakening of the vortex. The first would be the direct modulation of the winter polar temperatures through the increase in stratospheric warming events which cool the mesosphere. This would directly modulate the winter mesospheric temperatures in regions affected by the breakdown of the vortex. The second mechanism, the inter-hemispheric coupling of the winter vortex changes discussed here, would modulate only the summer mesospheric temperatures. Thus, a QBO modulation of mesospheric temperatures would not be expected in the Antarctic observations within the vortex, since the vortex core is stable during the winter observations (Baldwin and Dunkerton, 1998; Kuroda and Kodera, 2001; Karlsson et al., 2007) and no summer measurements of the hydroxyl are available during the polar day. Similarly, stratospheric warming events would not be expected to have a large effect on northern mid-latitude observations that are far outside the polar vortex. However, the near-infrared measurements presented here from $\sim 60^{\circ} \mathrm{N}$ are within the influence of stratospheric warming events during winter, but at a low enough latitude such that summertime observations are possible.

An interesting effect of the QBO modulation occurring only during certain seasons is that it would create a nonlinear interaction between the QBO and the annual cycle of polar mesospheric temperatures that is the analogue of that found for polar stratospheric temperatures (Salby et al., 1997; Salby and Callaghan, 2000). This would mean that if the data were stratified according to the QBO phase, this nonlinear interaction would produce an 11-year oscillation in the two data sets even if none were present in the original signal. In the few cases where mesospheric temperature data have been biennially sampled (Neuman, 1990; Nikolashkin, 2001), this sampling artefact could have enhanced the inferred solar-cycle signal.

Finally, while this investigation has found the polar summer mesopause temperatures to be modulated by the QBO, with the warm anomalies occurring during an easterly phase of the SQBO, Fig. 4 shows that they occur during a westerly phase of the MQBO. A number of workers (Jarvis, 1996; Espy et al., 1997; Jarvis, 1997; Hibbins et al., 2007, 2009) have shown that the westerly MQBO winds form a wave guide that allows westward tidal- and planetary-wave energy to migrate from the winter hemisphere into the summer mesosphere. The dissipation of this additional wave energy there would serve to enhance the warm temperature anomalies, strengthening the QBO modulation of the summer temperatures. However, the presence of waves with periods greater than $\sim 6 \mathrm{~h}$ has been shown to amplify PMC in the summer mesosphere (Rapp et al., 2002), offsetting the effect on PMC. Thus the use of temperature proxies based on PMC properties should be used cautiously.

In conclusion, we have used a ten-year time series of July mesospheric temperatures near $60^{\circ} \mathrm{N}$ derived from the hydroxyl $(\mathrm{OH})$ nightglow to confirm the correlation of polar summer mesospheric temperatures with the polar winter stratospheric temperatures that was found by Karlsson et al. (1997) using proxy data. There was a phase-coherent oscillation at the period of the QBO in both winter stratospheric and summer mesospheric temperatures. The sign and phase of the correlation is consistent with the QBO modulation of the extra-tropical stratospheric dynamics in the Southern Hemisphere via the Holton-Tan mechanism (Holton and Tan, 1980). This lends strength to the identification of synoptic and planetary waves as the driver of the inter-hemispheric coupling, and results in a strong QBO modulation of the polar summer mesospheric temperatures.

Acknowledgements. The authors wish to acknowledge the support from the Erasmus programme of European Commission as well as the financial support from the Swedish National Science Research Council and the Swedish Board for Space Activities.

Edited by: F.-J. Lübken

\section{References}

Baker, D. J. and Stair Jr., A. T.: Rocket measurements of the altitude distributions of the hydroxyl airglow, Physica Scripta, 37, 611622, 1988.

Baldwin, M. P. and Dunkerton, T. J.: Quasi-biennial modulations of the Southern Hemisphere stratospheric polar vortex, Geophys. Res. Lett., 25, 3343-3346, 1998.

Baldwin, M. P., Gray, L. J., Dunkerton, T. J., Hamilton, K., Haynes, P. H., Randel, W. J., Holton, J. R., Alexander, M. J., Hirota, I., Horinouchi, T., Jones, D. B. A., Kinnersley, J. S., Marquardt, C., Sato, K., and Takahashi, M.: The quasi-biennial oscillation, Rev. Geophys., 39, 179-229, 2001.

Becker, E., Müllemann, A., Lübken, F.-J., Körnich, H., Hoffmann, P., and Rapp M.: High Rossby-wave activity in austral winter 2002: Modulation of the general circulation of the MLT during the MaCWAVE/MIDAS northern summer program, Geophys. Res. Lett., 31, L24S03, doi:10.1029/2004GL019615, 2004.

Berk, A., Bernstein, L. S., and Robertson, D. C.: MODTRAN: A Moderate Resolution Model for LOWTRAN 7. Air Force Geophysics Laboratory Technical Report GL-TR-89-0122, Hanscom AFB, MA, 1989.

Bittner, M., Offermann, D., Graef, H. H., and Donner, M.: Wavelet analysis of upper mesosphere temperature variations, Adv. Space Res., 21, 1445-1448, 1998.

Bittner, M., Offermann, D., and Graef, H. H.; Mesopause temperature variability above a midlatitude station in Europe, J. Geophys. Res., 105, 2045-2058, 2000. 
Bittner, M., Offermann, D., Graef, H. H., Donner, M., and Hamilton, K.: An 18-year time series of $\mathrm{OH}$ rotational temperatures and middle atmosphere decadal variations, J. Atmos. Sol.-Terr. Phys., 64, 1147-1166, 2002.

Burrage, M. D., Vincent, R. A., Mayr, H. G., Skinner, W. R., Arnold, N. F., and Hays, P. B.: Long-term variability of the equatorial middle atmosphere zonal wind, J. Geophys. Res., 101, 12847-12854, 1996.

Dunkerton, T. J. and Baldwin, M. P.: Quasi-biennial modulation of planetary wave fluxes in the northern hemisphere winter, J. Atmos. Sci., 48, 1043-1061, 1991.

Espy, P. J. and Stegman, J.: Trends and variability of mesospheric temperature at high-latitudes, Phys. Chem. Earth, 27, 543-553, 2002.

Espy, P. J., Huppi, R., and Manson, A.: Large scale, persistent latitude structures in the mesospheric temperature during ANLC-93, Geophys. Res. Lett., 22, 2801-2804, 1995.

Espy, P. J., Stegman, J., and Witt, G.: Interannual variations of the quasi-16-day oscillation in the polar summer mesospheric temperature, J. Geophys. Res., 102, 1983-1990, doi:10.1029/96JD02717, 1997.

French, W. J. R. and Burnes, G. B.: The influence of large-scale oscillations on long-term trend assessment in hydroxyl temperatures over Davis, Antarctica, J. Atmos. Sol.-Terr. Phys., 66, 493506, 2004.

Fritts, D. C. and Alexander, M. J.: Gravity wave dynamics and effects in the middle atmosphere, Rev. Geophys., 41(1), 1003, doi:10.1029/2001RG000106, 2003.

Fritts, D. C. and Luo, Z. G.: Dynamical and radiative forcing of the summer mesopause circulation and thermal structure. 1. Mean solstice conditions, J. Geophys. Res., 100, 3119-3128, 1995.

Giorgetta, M. A. and Manzini, A.: Forcing of the quasi-biennial oscillation from a broad spectrum of atmospheric waves, Geophys. Res. Lett., 29, 1245, doi:10.1029/2002GL014756, 2002.

Holton, J. R.: The role of gravity wave induced drag and diffusion in the momentum budget of the mesosphere, J. Atmos. Sci., 39, 791-799, 1982.

Holton, J. R.: The influence of gravity wave breaking on the general circulation of the middle atmosphere, J. Atmos. Sci., 40, 24972507, 1983.

Holton, J. R. and Tan, H.-C.: The influence of the equatorial quasibiennial oscillation on the global circulation at $50 \mathrm{mb}$, J. Atmos. Sci., 37, 2200-2208, 1980.

Jarvis, M. J.: Quasi-biennial oscillation effects in the semidiurnal tide of the Antarctic lower thermosphere, Geophys. Res. Lett., 23, 2661-2664, doi:10.1029/96GL02394, 1996.

Jarvis, M. J.: Latitudinal variation of quasi-biennial oscillation modulation of the semidiurnal tide in the lower thermosphere, J. Geophys. Res., 102, 27177-27187, doi:10.1029/97JA02034, 1997.

Hibbins, R. E., Espy, P. J., and Jarvis, M. J.: Quasi-biennial modulation of the semidiurnal tide in the upper mesosphere above Halley, Antarctica, Geophys. Res. Lett., 34, L21804, doi:10.1029/2007GL031282, 2007.

Hibbins, R. E., Jarvis, M. J., and Ford, E. A. K.: Quasi-biennial oscillation influence on long-period planetary waves in the Antarctic upper mesosphere, J. Geophys. Res., 114, D09109, doi:10.1029/2008JD011174, 2009.

Hill, R. A., Mulac, A. H., Aeschliman, D. P., and Flower, W. L.:
Teperatures from rotational-vibrational Raman Q-branches, J. Quant. Spectrosc. Ra., 21, 213-220, 1979.

Karlsson, B., Körnich, H., and Gumbel, J.: Evidence for interhemispheric stratosphere-mesosphere coupling derived from noctilucent cloud properties, Geophys. Res. Lett., 34, L16806, doi:10.1029/2007GL030282, 2007.

Karlsson, B., McLandress, C., and Shepherd, T.G.: Interhemispheric mesospheric coupling in a comprehensive middle atmosphere model, J. Atmos. Sol. Terr. Phys., 71, 518-530, doi:10.1016/j.jastp.2008.08.006, 2009.

Körnich, H. and Becker, R.: A simple model for the interhemispheric coupling of the middle atmosphere circulation, Adv. Space Res., 45, 661-668, 2010.

Kuroda, Y. and Kodera, K.: Variability of the polar night jet in the Northern and Southern Hemispheres, J. Geophys. Res., 106, 20703-20713, 2001.

Lowe, R. P., LeBlanc, L. M., and Gilbert, K. L.: WINDII/UARS ovservations of twilight behaviour of the hydroxyl airglow, at mid latitude equinox, J. Atmos. Terr. Phys., 58, 1863-1869, 1996.

Lübken, F.-J., von Zahn, U., Manson, A., Meek, C., Hoppe, U.-P., Schmidlin, F. J., Stegman, J., Murtagh, D. P., Rüster, R., Schmidt, G., Widdel, H.-U., and Espy, P.: Mean state densities, temperatures and winds during the MAC/SINE and MAC/EPSILON campaigns, J. Atmos. Terr. Phys., 52, 955-970, 1990.

Luo, Z. G., Fritts, D. C., Portmann, R. W., and Thomas, G. E.: Dynamical and radiative forcing of the summer mesopause circulation and thermal structure. 2. Seasonal-variations, J. Geophys. Res., 100, 3129-3137, 1995.

Mcintyre, M. E.: How well do we understand the dynamics of stratospheric warmings?, J. Meteorol. Soc. Jpn., 60, 37-65, 1982.

Maillard, J. P., Chauville, J., and Mantz, A. W.: High resolution emission spectrum of $\mathrm{OH}$ in an ocyacetylne flame from 3.7 to $0.9 \mu \mathrm{m}$, J. Mol. Spec., 63, 120-141, 1976.

Mies, F. H.: Calculated vibrational transition probabilities of $\mathrm{OH}\left(\mathrm{X}^{2} \Pi\right)$, J. of Mol. Spec., 53, 150-188, 1974.

Neumann, A.: QBO and solar activity effects on temperatures in the mesopause region, J. Atmos. Terr. Phys. 52, 165-173, 1990.

Nikolashkin, S. V., Ignatyev V. M., and Yugov, V. A.: Solar activity and QBO influence on the temperature regime of the subauroral middle atmosphere, J. Atmos. Sol.-Terr. Phys., 63, 853-868, 2001.

O'Sullivan, D. and Salby, M. L.: Coupling of the quasi-biennial oscillation and the extratropical circulation in the stratosphere through planetary wave transport, J. Atmos. Sci., 47, 650-673, 1990.

O'Sullivan, D. and Young, R. E.: Modeling the quasi-biennial oscillation's effect of the winter stratospheric circulation, J. Atmos. Sci., 49, 2437-2448, 1992.

Pendleton Jr., W. R., Espy, P. J., and Hammond, M. R.: Evidence for Non-Local-Thermodynamic-Equilibrium rotation in the $\mathrm{OH}$ Nightglow, J. Geophys. Res., 98, 11567-11579, 1993.

Pertsev, N. and Perminov, V.: Response of the mesopause airglow to solar activity inferred from measurements at Zvenigorod, Russia, Ann. Geophys., 26, 1049-1056, doi:10.5194/angeo-261049-2008, 2008.

Randel,W. J., Shine, K. P., Austin, J., Barnett, J., Claud, C., Gillett, N. P., Keckhut, P., Langematz, U., Lin, R., Long, C., 
Mears, C., Miller, A., Nash, J., Seidel, D. J., Thompson, D. W. J., Wu, F., and Yoden, S.: An update of observed stratospheric temperature trends, J. Geophys. Res, 114, D02107, doi:10.1029:2008JD010421, 2009.

Rapp, M., Lübken, F.-J., Müllemann, A., Thomas, G. E., and Jensen, E. J.: Small-scale temperature variations in the vicinity of NLC: Experimental and model results, J. Geophys. Res., 107(D19), 4392, doi:10.1029/2001JD001241, 2002.

Salby, M. and Callaghan, P.: Connection between the Solar Cycle and the QBO: The Missing Link, J. Climate, 13, 328-338, 2000.

Salby, M., Callaghan, P., and Shea, D.: Interdependence of the tropical and extratropical QBO: Relationship to the solar cycle verses a biennial oscillation in the stratosphere, J. Geophys. Res., 102, 29789-29798, 1997.

Shepherd, M. G., Evans, W. F. J., Hernandez, G., Offermann, D., and Takahashi, H.: Global variability of mesospheric temperature: Mean temperature field, J. Geophys. Res., 109, D24117, doi:10.1029/2004JD005054, 2004.
Shepherd, M. G., Liu, G. G., and Shepherd, G. G.: Mesospheric semiannual oscillation in temperature and nightglow emission, J. Atmos. Sol.-Terr. Phys., 68, 379-389, 2006.

Uppala, S. M., Kållberg, P. W., Simmons, A. J., Andrae, U., da Costa Bechtold, V., Fiorino, M., Gibson, J. K., Haseler, J., Hernandez, A., Kelly, G. A., Li, X., Onogi, K., Saarinen, S., Sokka, N., Allan, R. P., Andersson, E., Arpe, K., Balmaseda, M. A., Beljaars, A. C. M., van de Berg, L., Bidlot, J., Bormann, N., Caires, S., Chevallier, F., Dethof, A., Dragosavac, M., Fisher, M., Fuentes, M., Hagemann, S., Hólm, E., Hoskins, B. J., Isaksen, L., Janssen, P. A. E. M., Jenne, R., McNally, A. P., Mahfouf, J.-F., Morcrette, J.-J., Rayner, N. A., Saunders, R. W., Simon, P., Sterl, A., Trenberth, K. E., Untch, A., Vasiljevic, D., Viterbo, P., and Woollen, J.: The ERA-40 re-analysis, Q. J. Roy. Meteorol. Soc., 131, 2961-3012, 2005.

Xu, J., Smith, A. K., Yuan, W., Liu H.-L., Wu, Q., Mlynczak, M. G., and Russell III, J. M.: Global structure and long-term variations of zonal mean temperature observed by TIMED/SABER, J. Geophys. Res., 112, D24106, doi:10.1029/2007JD008546, 2007. 